\title{
Forty years of business research in China: a critical reflection and projection
}

Ji-Ye Mao

Correspondence: maojiye@rmbs.ruc. edu.cn

Business School, Renmin University of China, Beijing 100872, China

\begin{abstract}
Indigenous business research has largely mirrored the economic growth in China over the past 40 years, which has reached a critical juncture. It is, therefore, important to take stock of the past progress to identify critical success factors and remaining challenges, in searching for paths to the next leap forward. To this end, this commentary will first review the key milestones in indigenous business research over the past four decades. Then it will highlight two paradoxes, namely, the lack of indigenous theories despite the phenomenal growth of Chinese firms, and the growing divergence between scientific rigor and low relevance to practice, which will need to be addressed in the future. Lastly, several predications and suggestions will be offered.
\end{abstract}

Keywords: Indigenous business research, Contextualized research, Business research in China

\section{Preamble}

This year marks the 40th anniversary of China's reform and opening up commenced in late 1978, which has fundamentally transformed the nation and lifted it out of poverty to a large extent. After four decades of phenomenal growth, the nation has reached a critical junction, and is now searching for both new directions and drivers for the next round of growth, while trying to steer away from the middle income trap. Despite the phenomenal growth in the past, there are structural problems in the economy that are difficult and painful to resolve after low hanging fruits have been picked up. However, it is also clear that the old path of growth is no longer sustainable, and a new mode of growth is overdue.

In many ways, progress in business research in China has mirrored the growth pattern of the Chinese economy, and registered an equally impressive growth curve. Whereas the economic success is widely known to the world as reflected in not only all kinds of statistics but also everyday living, few have a reasonable grasp of the nature and extent of progress in business research in China, nor the remaining challenges and opportunities. China has emerged as a top producer of business research papers in both quantity and influence measured in citations (Li 2015). Whereas the notion of empirical business research was entirely alien to Chinese researchers till late 1980s, it is now firmly entrenched in the academia. Similar to the current state of the economy, business research in China also needs another round of transformation, in order to

(c) The Author(s). 2018 Open Access This article is distributed under the terms of the Creative Commons Attribution 4.0 International License (http://creativecommons.org/licenses/by/4.0/), which permits unrestricted use, distribution, and reproduction in any medium, provided you give appropriate credit to the original author(s) and the source, provide a link to the Creative Commons license, and indicate if changes were made. 
establish its own identity and to make greater contributions to the global community of business researchers.

It is against such a backdrop that this commentary is composed with a threefold purpose. First, it will briefly take stock of the transformation of business research from nearly nonexistence to a flourishing state demonstrated by both the quantity and quality of publications. Second and third, it will identify key challenges and contradictions, and to speculate on future directions.

\section{An overview of the past progress}

Business research in China has made remarkable strides over the past four decades. Whereas it is important to take stock, neither is it desirable nor feasible to present a complete historical review of the development process in this commentary. Instead, it shall present a brief overview only, while highlighting several key milestones as the background for the critical reflection to follow.

In a comprehensive review of business research in China over the period between 1978 to 2008 based on a survey of senior Chinese scholars in the field, Su and Liu (2009) identified 55 important milestones and divided the development history of business research in China into three stages, the awareness stage (1978-1986), formation stage (1987-1996), and rapid development stage (since 1997). During the awareness stage, the importance of business research was gradually recognized by the state, firms, and academia. However, previously there was no real research on market-oriented modern organizations beyond isolated exploration on productivity enhancement, because enterprises followed executive orders from the state as part of the planned economy. Hardly was there any indigenous management research based on generally adopted research methodologies by Western researchers, be it empirical or mathematical. Research at that time was largely translating Western textbooks and preparing lecture notes.

During the formation stage, business research gained formal recognition by major stakeholders, and was institutionalized, especially after Deng Xiaoping's famous tour in southern China, where he called for greater degrees of adamant reform and opening up in the spring of 1992. This was a landmark event in modern Chinese history, which jump-started the then stagnating reform and accelerated the pace of transformation in all sectors including science and technology development. Gradually, business research was recognized as an academic discipline by the state authorities. In particular, the management sciences division of the national Natural Science Foundation of China (NSFC) was promoted to a full-fledged department as other recognized disciplines in 1996, 10 years after the diversion's establishment from the very beginning of the NSFC. The first MBA programs were also launched in several universities on a trial basis in 1990, which stimulated business research and created the need for researchers.

Lastly, since 1997 business research as an academic discipline entered a stage of rapid growth. Two events significantly shaped the subsequent development in particular. First, through its newly formed Management Sciences Department, ${ }^{1}$ the NSFC became the primary source of funding to business researchers and provided the largest research grants on average to scientists on a competitive basis. The success rate has always been under $20 \%$, and used to be much lower hovering above the $10 \%$ mark, and thus a grant from NSFC carried high esteem. Applications were subjected to a peer review process, which weighed heavily the soundness of the research methodology and scientific rigor 
in particular. The influence of the NSFC was partly reflected in the funding for papers published in English language journals. According to a report by the Management Science Department of the NSFC (Li, 2015), in 2009 among the papers authored by Chinese mainland-based researchers and were indexed by the Web of Science (WoS), $37 \%$ of them were funded by the NSFC, far ahead of under $8 \%$ funded by the Ministry of Education, the second largest source of research funding. These two ratios rose to $47 \%$ and $15 \%$, respectively, in 2013 , while the rest were funded by the third to the fifth largest national funding sources including the Ministry of Science and Technology, and the Ministry of Human Resources and Social Security of China. 66\% of the highly cited papers were funded by NSFC in 2013. Clearly, NSFC has established its position as the primary funding source for business research in China. Second, also during this stage, Professor Anne Tsui, organized a series of workshops on empirical business research methodology at the Hong Kong University of Science and Technology, from 1999 to 2002. The workshops rightfully targeted junior faculty in Chinese universities, and each trained dozens of junior researchers, who later became academic leaders in their own institute and respective research field.

\section{Paradox 1: Business success vs. lack of indigenous theories}

As a result of the rapid growth of Chinese economy over the past four decades, the number of Chinese companies in the global Fortune 500 has reached 115 in 2017, including 109 based in Chinese mainland and Chinese Hong Kong (Fortune, 2017). Not only in size but also in quality and innovation have Chinese companies managed to grow. China is leading the world or among the frontrunners in e-commerce, mobile payment, sharing economy, artificial intelligence, 3D printing, and pilotless planes. The top four e-commerce giants BATJ (an acronym to refer to Baidu, Alibaba, Tencent, and JD.com, and especially Alibaba and Tencent) are powering new business models in the name of New Retail, which refers to the combination of omni-channels (online and offline), socialization in addition to merely retail transactions, and the use of big data to personalize consumer experiences. However, no well-known management tool, method, concept, or theory has emerged from best practices of Chinese firms, let alone anything generalizable and adopted beyond a single company. In contrast, during the late 1980s and later, when the success of Japanese firms produced new manufacturing methodologies such as lean manufacturing, the Kanban system, just-in-time inventory management, popularized by the Toyota Production System.

It begs the question of how have the Chinese firms achieved the phenomenal growth? Is there a distinctive growth model or winning formula for corporate China? Or is Chinese firms' success largely due to the large size of the domestic market protected by a unique institutional environment, and the so-called population dividend and latecomer advantage? Alternatively, is it because indigenous research has turned a blind eye to the best practices of Chinese firms? My personal view is that the past success of Chinese firms was largely attributable to the shortage economy featured in the early stage of reform and opening up and lasted till earl 2010s when the economy has maintained a high growth rate. There was a huge demand from consumers for any product of reasonable quality and price. In other words, just riding the rising tides was good enough for corporate China. Moreover, it is likely because that Chinese firms have been playing a catch up game, and achieved success simply by adopting well-established 
Western managerial processes and methods and sometimes creatively adapting these to the local context. As an anecdote, a former colleague of mine and a long-time senior advisor to Huawei, widely considered the most successful Chinese firm, believed that the most important success factor of Huawei was continuously adopting Western management processes and methodologies such as the Integrated Product Development process of IBM. To date, the best-known new to the world and originated from China method, "Rendanheyi," which means to align every employee to customer requirements in order to produce quality product to satisfy customer needs, is a methodology proposed by Haier's supreme leader Mr. Zhang Ruimin. However, it has hardly been studied by Chinese researchers, nor was it widely adopted beyond Haier. Therefore, there exists hardly any evidence of its effectiveness, let alone theorizing around the method.

\section{Paradox 2: Divergence between research rigor and relevance}

According to the same report by the Management Science Department of the NSFC (Li, 2015), in 2004, Chinese researchers published only 682 papers referenced in the $\mathrm{SCI} / \mathrm{SSCI}$ (WoS) databases, which could be considered an indicator of quality, and this number rose to 5288 after an impressive 6.8 fold increase in 2013 only after that of the US and the UK, 19,221 and 7063, respectively. More importantly, the number of citations per paper, which is often taken as a measure of quality and influence, by Chinese researchers in the SCI/SSCI databases is ranked the second in the world, only after that of the Netherlands. In fact, two Chinese business schools have broken into the top 100 in the world in the University of Texas at Dallas list of top 24 business research journals. All of these indicate that business research by Chinese scientists has achieved an acceptable degree of methodological maturity and scientific rigor.

However, the practical impact of the business research has been minimal. Part of the reason is that junior researchers in the top-tier business schools are hired from overseas with solid training to produce high quality research, but the research support and culture are not always up to the standard in the elite research schools in the US. Promotion and other incentives disproportionally favor research excellence, i.e., publications are preferred by peers who also prefer rigor to relevance. In contrast with the past, at least some of the earlier generations of business faculty have worked closely with the industry, e.g., the well-known Six Gentlemen for Huawei, i.e., the six professors from Renmin University of China, who advised Huawei and helped its success in its early years. However, by and large, few faculty hired over the past two decades are focused on applied research or choose to closely engage the business world. Many researchers have taken notice of this disturbing fact that research papers are increasingly more methodologically rigorous, but less and less relevant to practice, to the extent that research papers are neither targeting practitioners, nor are they used in classroom teaching. For many researchers, publication is just for the sake of it, and this situation is due for a change.

Regrettably, existing research papers on business administration in China virtually show no signs of indigenous characteristics (Tsui and Zhang 2011). As a result, no adequate progress has been made to address the criticisms on Chinese or Asian management research in general, such as the lack of self-confidence (Meyer 2006), weaknesses in theory development or relevance for management 
practices (White 2002), and heavily utilizing existing management theories but rarely proposing new theories (Tsui, 2009).

Despite the two paradoxes and challenges discussed earlier, a quantum leap has been made in business research in China. It is because scientific rigor must be established first, which was needed the most over the past 40 years, i.e., addressing the primary weakness head-on. In other words, the past success has laid a solid foundation for the future. Rigor will remain the most important issue for the years ahead. In the past, the effort was well spent on catching up the methodology of organizational research. Therefore, Chinese researchers should stick to the winning-formula and keep pursuing methodological rigor continuously.

\section{Future directions}

Next, this commentary will conclude with several suggestions for ways to move forward, and some practical advice.

First, it could be highly promising for Chinese researchers to address questions that target indigenous management problems. Unfortunately, not enough has been done in this regard. In a review of 270 empirical research papers related to Chinese contexts published in six top-tier general management journals in the world over the previous three decades till 2010 and Management and Organization Review (MOR) from its launch in 2005 to 2010, Jia et al. (2012) found that only 10 of the 270 featured some degree of Chinese contextualization in their concepts or constructs, relationships, and the logics underlying the relationships. A key conclusion was that Chinese-context-centered studies only offered three new concepts, market transition, network capitalism, and guanxi, though they have re-conceptualized concepts such as trust, citizenship behavior, and emotional intelligence. However, the Chinese context has failed to contribute new theoretical logics, except for Confucianism and related concepts such as guanxi, face, wulun, renqing, and traditionality. Interestingly, Li and Tsui (2002) showed that impactful studies (measured by citations) tend to have strong indigenous features, which means contextual factors are the key in theory-building as independent variables or moderators.

Not only is contextualized research theoretically important, but also increasingly feasible and practical. Whereas China has emerged as the world factory, it has also become the largest laboratory for organization research. Given the fast pace and magnitude of changes in Chinese firms, many interesting phenomena are amplified and intensified, and thus could be easier to observe. For example, the continuous reform and associated frequent policy changes combined with the technology advance and globalization, the operating environment for Chinese firms are particularly dynamic, which make it ideal for advancing theories on dynamic capabilities, and strategic transformation. A personal anecdotal example is what I have observed from my own research on IT outsourcing. Whereas most existing research on offshore IT outsourcing adopted a client perspective because the research was conducted by researchers in the West, I had access to Chinese IT vendors only when I started my research in this area in 2004 in China. This limitation was turned into an opportunity that allowed me to fill a gap in the literature from a vendor's perspective (Jarvenpaa and Mao 2008) and to complement the existing research. Similar opportunities exist in areas that China is on the leading edge such as e-commerce, 3D printing, pilotless plains, AI applications, and shared economies. 
Chinese researchers have an opportunity to make unique contributions in these areas to the global management community.

Moreover, from a practical perspective, it is also important to contextualize business research. Situated in a unique political, social, and cultural environment, Chinese firms have to overcome numerous unique challenges. In particular, given the size of the Chinese economy, Chinese researchers shoulder a heavy responsibility to help domestic firms with their research, and thus must pay attention to critical issues of practical importance to the development of these firms. They should not simply recycle Western theories and turn a blind eye to critical issues faced by Chinese companies, though it might make sense for researchers in a small nation or region to overlook local issues. It is the responsibility of Chinese researchers to conduct research that is relevant to the local practice. Through solving real management problems, useful theories can be developed. Therefore, more effort should be directed to local management issues, which could also yield high return. As an increasing number of companies are operating on the global stage and becoming multinational, critical issues to Chinese firms can be highly relevant and of interest to firms in other emerging economies as well as the developed world. As a popular Chinese saying suggests, the more national, the more international.

Second, Chinese researchers should ask theoretically important questions in their research, which is the prerequisite for any high impact research and highly regarded by researchers as part of the current paradigm of research. To this end, indigenous research must engage in a dialogue with the mainstream literature and frontiers of business research in the world, to identify a major gap or weaknesses in the extant research. After all, any research contribution is an extension or revision of the existing theories.

Third, there is a growing need to embrace the diversity in research methods. Whereas traditional empirical research has primarily used questionnaire-based survey data, today it is increasingly more important to extend the traditional data collection to the macro end or the micro end, i.e., big data or case-based rich data. In particularly, qualitative research, which tends to be case-based (Eisenhardt 1989; Eisenhardt and Graebner 2007) for inductive theory development has gained more traction in recent years (Mao and Su 2016) because of case studies' advantages in creating new discoveries and new insights. The comparative advantages of qualitative research are important for theory-building that is grounded in complex real-world problems. Case studies and inductive qualitative research in general can be expected to be used more widely to address the issues identified by Tsui (2009), "research in Chinese management has exploited existing questions, theories, constructs, and methods developed in the Western context. Lagging are exploratory studies to address questions relevant to Chinese firms and to develop theories that offer meaningful explanations of Chinese phenomena" (p. 1).

Meanwhile, the arrival of the big data era has also provided exciting opportunities for collecting massive high quality data, as Chinese firms such as China Mobile, China Life, Alibaba, and Tencent, possess the largest databases in the world. Again, Chinese researchers have an advantages because they are closer to the big data sources than their Western colleagues, and research collaboration between local and overseas researchers can yield high quality publications in top-tier journals. 
Fourth and lastly, the past progress in business research can be attributed to international collaboration, as over $50 \%$ of the top-tier journals published in management sciences with funding from NSFC involved collaboration with co-authors affiliated with overseas institutions (Li 2015). International collaboration brought in not only methodological rigor, but also experience in theorizing, which takes a long career to develop, given that empirical research in business administration began only in the mid-1990s. A casual observation of the top-tier journal publications by Chinese mainland-based researchers, the majority of whom have a doctoral degree overseas, reveals that they are usually the result of international collaboration with more established overseas co-authors. A complementary strength of the local researchers is their close engagement with the frontline innovation and best-practices by Chinese companies, while their overseas collaborators are more experienced with the revision and publication process. It is safe to expect that international collaboration will remain important. The biennial conference of the International Association for Chinese Management Research (IACMR) has been instrumental in promoting the engagement between local Chinese researchers and those overseas. Therefore, in the future Chinese business researchers have both the need and means to extend the scope and deepen the depth of international collaboration.

In essence, it is all about adopting scientific rigor, i.e., to tell the Chinese stories with an international language. Clearly indigenous business research is poised to make the next leap forward. This journal, Frontiers of Business Research in China, which is also a by-product of the reform and opening up, is committed to becoming a premier outlet for high quality business research with strong implications for management in China.

\section{Conclusions}

In sum, over the past four decades, business research in China has completed a full circle of spiral climb by adopting international standards and scientific rigor in methodology. This has laid a solid foundation for the next round of climbing. It also is important to identify the critical success factors of the past success, and how to leverage the past success. This research commentary reviews the key milestones in indigenous business research over the past four decades to commemorate the 40th anniversary of the reform and opening up in China. It also highlights two paradoxes, i.e., the lack of indigenous theories despite the phenomenal growth of Chinese firms, and the growing divergence between scientific rigor and low relevance to practice, which will need to be addressed in the future. Lastly, several predications and suggestions are offered to address the two paradoxes. First, more effort should be directed to local management issues. A particularly fruitful future avenue would be to contextualize research, i.e., to more closely examine unique challenges and issues faced by indigenous Chinese companies while staying more relevant to the local businesses. Second, indigenous research must engage in a dialogue with the mainstream literature and frontiers of business research in the world so that important research questions can be asked and theoretical contributions can be made. Third, there is a growing need to embrace the diversity in research methods such as qualitative research and big-data based approaches. Fourth and lastly, Chinese business researchers should extend the scope and deepen the depth of international collaboration, which was a critical success factor in the past. 


\section{Endnotes}

${ }^{1}$ The department covers three narrower disciplines of management sciences, including operations research, business administration, and public administration and managerial economics. The term management sciences will be used with the same meaning subsequently.

\section{Acknowledgements}

The author would like to acknowledge the funding from the MOE Project of Key Research Institute of Humanities and Social Sciences at Universities (Project No. 10JJD630012).

\section{Funding}

This study was supported by the MOE Project of Key Research Institute of Humanities and Social Sciences at Universities (Project No. 10JJD630012).

\section{Availability of data and materials}

There is no first hand data collection for this work. All data cited in this work has been given the original source in references.

\section{Author's contribution}

JYM is the sole author of the commentary. The author read and approved the final manuscript.

\section{Competing interests}

The author declares that he has no competing interests.

\section{Publisher's Note}

Springer Nature remains neutral with regard to jurisdictional claims in published maps and institutional affiliations.

Received: 15 November 2018 Accepted: 20 November 2018

Published online: 13 December 2018

\section{References}

Eisenhardt, K. M. (1989). Building theories from case study research. Academy of Management Review, 14(4), 532-550.

Eisenhardt, K. M., \& Graebner, M. E. (2007). Theory building from cases: Opportunities and challenges. Academy of Management Journal, 50(1), 25-32.

Fortune. 2017 Fortune 500 list. http://www.fortunechina.com/fortune500/c/2017-07/20/content_286785.htm, accessed on October 21, 2018.

Jarvenpaa, S. L., \& Mao, J.-Y. (2008). Operational capabilities development in mediated offshore software services models. Journal of Information Technology, 23(3), 3-17.

Jia, L., You, S., \& Du, Y. (2012). Chinese context and theoretical contributions to management and organization research: A three decade review. Management and Organization Review, 8(1), 173-209.

Li, J. T., \& Tsui, A. S. (2002). A citation analysis of management and organization research in the Chinese context: 1984 to 1999. Asia Pacific Journal of Management, 19(1), 87-107.

$\mathrm{Li}, \mathrm{Y}$ 李一军, (2015). 管理科学基础研究“十三・五”学科发展的若干思考 (Several considerations on basic research in management sciences in the 13th Five Year Plan). 国家自然科学基金委管理科学部内部报告 (An Internal Report of the Management Sciences Department, Natural Science Foundation of (hina).

Mao, J毛基业, \& Su, F苏芳, (2016). 案例研究的理论贡献——中国企业管理案例与质性研究论坛(2015)综述 (Making theoretical contributions with case studies-Review of the forum on case-based and qualitative research (2015).管理世 界 (Management World), 2016(2), 128-132.

Meyer, K. E. (2006). Asian management research needs more self-confidence. Asia Pacific Journal of Management, 23(2), 119-137.

Su, Y苏勇, \& Liu, G刘国华, (2009). 中国管理学发展进程: 1978 2008 (The development process of Chinese management research: 1978-2008). 经济管理 (Economic Management Journa), 31(1), 164-172.

Tsui, A. S. (2009). Autonomy of inquiry: Shaping the future of emerging scientific communities. Management and Organization Review, 5(1), 1-14.

Tsui, A徐淑英, \& Zhang, Z张志学, (2011). 管理问题与理论建立:开展中国本土管理研究的策略 (Research questions and theory-development: Strategies for indigenous management research). 重庆大学学报(社会科学版) (Journal of Chongaing University (Social Science Edition)), 19(4), 1-7.

White, S. (2002). Rigor and relevance in Asian management research: Where are we and where can we go? Asia Pacific Journal of Management, 19(2-3), 287-352. 